\title{
CD226 Gly307Ser Association With Neuromyelitis Optica in Southern Han Chinese
}

\author{
Chao Liu, Guansan Wang, Hong Liu, Yue Li, Jin Li, Yongqiang Dai, \\ Xueqiang $\mathrm{Hu}$
}

\begin{abstract}
Background: Neuromyelitis optica (NMO) and multiple sclerosis (MS) are autoimmune diseases of the central nervous system with complex pathogeneses. NMO was once considered to be a severe variant of MS. There has been more evidence that a nonsynonymous exchange (rs763361/Gly307Ser) in the gene for CD226 is linked to several autoimmune diseases including multiple sclerosis (MS). However, no studies have investigated the role of rs763361 in the pathogenesis of NMO. Objectives: The goal of our study is to evaluate the role of CD226 Gly307Ser in neuromyelitis optica (NMO) in Southern Han Chinese. Methods: Eight-nine NMO patients, 93 relapsing-remitting multiple sclerosis (RRMS) patients, and 122 controls (CTLs) were enrolled. The rs763361 alleles of the subjects were determined by sequencing-based typing. Results: The results strongly support that the TT genotypes are associated with NMO but are not significantly correlated with susceptibility for MS. Conclusions: CD226 Gly307Ser may correlate with risk of NMO in Southern Han Chinese.
\end{abstract}

RÉSUMÉ: Association de la variante Gly307Ser du gène CD226 avec la neuromyélite optique chez les Chinois Han du Sud. Contexte : La neuromyélite optique (NMO) et la sclérose en plaques (SP) sont des maladies autoimmunes du système nerveux central dont la pathogenèse est complexe. La NMO était anciennement considérée comme une variante sévère de la SP. Il existe maintenant des données supplémentaires en faveur de l'hypothèse selon laquelle un échange non-synonyme (rs763361/Gly307Ser) dans le gène CD226 serait lié à plusieurs maladies autoimmunes dont la SP. Cependant, aucune étude n'a porté sur le rôle de rs763361 dans la pathogenèse de la NMO. Objectifs : Le but de notre étude était d'examiner le rôle de la variante Gly307Ser du gène CD226 dans la NMO chez les Chinois Han du Sud. Méthode : Quatre-vingt-neuf patients atteints de NMO, 93 patients atteints de SP récurrente-rémittente et 122 sujets témoins ont participé à l'étude. La présence de l'allèle rs763361 chez les sujets a été déterminée par séquençage. Résultats : Les résultats sont en faveur d'une association entre le génotype TT et la NMO, mais il n'existe pas de corrélation significative entre ce génotype et la susceptibilité à la SP. Conclusions : La variante Gly307Ser du gène CD226 pourrait être corrélée au risque de la NMO chez les Chinois Han du Sud.

Can J Neurol Sci. 2012; 39: 488-490

Neuromyelitis optica (NMO) and multiple sclerosis (MS) are autoimmune diseases of the central nervous system with complex pathogeneses. Evidence suggests that genetic and environment factors may induce these diseases ${ }^{1-3}$. Neuromyelitis optica was once considered to be a severe variant of MS. Since 2004, serum anti-aquaporin-4 antibody (AQP4-Ab) has been suggested to be a reliable biomarker of $\mathrm{NMO}^{4}$.

HLA-DRB1 on chromosome $6 \mathrm{p} 21$ was the most remarkable genetic locus contributing to MS susceptibility. However, a large number of non-HLA single nucleotide polymorphisms (SNP) were also confirmed to increase the risk for $\mathrm{MS}^{5-7}$. In NMO, although HLA-DPB1 might be associated with susceptibility to $\mathrm{NMO}^{3,8,9}$, the effect on non-HLA SNPs in NMO have been less well studied ${ }^{10,11}$.

CD226 belongs to the immunoglobulin supergene family of receptors and was widely expressed on the $\mathrm{CD} 4^{+}$and $\mathrm{CD} 8^{+} \mathrm{T}$ cells, natural killer cells, monocytes, B cells and platelets. CD226 could lead to various biological responses, including target cell lysis and immune cell activation ${ }^{12}$. Rs763361/
Gly307Ser in the immune response gene CD226 on chromosome 18q22 may increase the susceptibility of multiple autoimmune diseases, such as Type 1 diabetes (T1D), autoimmune thyroid disease (AITD) and rheumatoid arthritis (RA) ${ }^{13,14}$. In Chinese Han population, rs763361 was also associated with systemic lupus erythematosus (SLE) ${ }^{15}$. Rs763361 was also found to be associated with MS in Western and Asian countries ${ }^{12,13,16}$. However, no studies have

\footnotetext{
From the Guangzhou Forensic Science Institution (Guangdong Provincial Key Laboratory of Forensic Genetic) (CL, GW, HL, YL); Multiple Sclerosis Center, Department of Neurology (JL, YD, XH), The Third Affiliated Hospital of Sun Yat-Sen University, Guangzhou, Guangdong Province, China.

Received November 16, 2011. Final Revisions Submitted February 15, 2012. Correspondence to: Xueqiang Hu, Multiple Sclerosis Center, Department of Neurology, The Third Affiliated Hospital of Sun yat-sen University, No.600 Tianhe Road, Guangzhou 510630, Guangdong Province, China.

Email: huxueqiangzssy@yahoo.com.cn
} 
investigated the role of rs763361 in the pathogenesis NMO and MS in Chinese Han population.

In this study, we investigated the frequency of rs763361 in NMO and MS patients in Chinese Han population, and analyzed the susceptibility risk of rs763361 in those patients.

\section{Materials ANd Methods}

\section{Patients and controls}

Eight-nine AQP4-Ab positive NMO patients (68 women, 21 men), whose mean of onset age was 28.73 years, were selected based on the 2006 Wingerchuk criteria ${ }^{17}$. Indirect immunofluorescence test systems for human AQP4-Ab detection from EUROIMMUN (EUROIMMUN Medizinische Labordiagnostika, Lübeck, Germany) were used. Ninety-three (57 women, 36 men) relapsing-remitting multiple sclerosis (RRMS) patients fulfilling the 2010 McDonald criteria ${ }^{18}$ were enrolled and the mean of onset age was 33.15. These patients were all enrolled from the MS database of the Third Affiliated Hospital of Sun Yat-Sen University. Patients with only recurrent myelitis, recurrent optic neuritis, or recurrent brainstem symptoms were excluded from this study. One hundred twentytwo consenting volunteers ( 84 women, 38 men) were recruited as controls (CTLs). The selected CTLs had no first-degree relative with autoimmune diseases. All the subjects were Southern Han Chinese and were born in Southern China. This study was approved by the Ethics Committee of the Third Affiliated Hospital of Sun Yat-Sen University.

\section{Genotyping}

Peripheral blood samples were Collected and stored at $-20^{\circ} \mathrm{C}$. Genome DNA was extracted by using the Tianamp N96 DNA Blood Kit (Tiangen, Beijing, China). The target DNA sequence was amplified by polymerase chain reaction (PCR) method with proper primer as followed: forward primer 5'GCACT CATGTCAAGAATAAG-3' and reverse primer 5'AAGTTCAGACACTGTGTTAG-3'. PCR amplification was performed with $50 \mathrm{ng}$ of genomic DNA in $20 \mu \mathrm{l}$ PCR reaction mixture containing $20 \mathrm{mM}$ Tris- $\mathrm{HCl} \mathrm{pH}$ 8.0, $50 \mathrm{mM}$ EDTA, 0.2 $\mathrm{mM}$ dNTPs, $1.5 \mathrm{mM} \mathrm{MgC}_{12}$, forward and reverse primers $(0.5$ $\mu$ mole each), 2.5 units of Taq polymerase. The PCR cycle consisted of a sequence of denaturation at $95^{\circ} \mathrm{C}$ for five minutes (min), denaturation at $94^{\circ} \mathrm{C}$ for $1 \mathrm{~min}$, annealing at $56^{\circ} \mathrm{C}$ for one min, extension at $72^{\circ} \mathrm{C}$ for one min. After 35 cycles reaction was terminated using a final extension at $72{ }^{\circ} \mathrm{C}$ for seven min. The PCR products were $480 \mathrm{bp}$. After standardization of the PCR conditions, sequencing was carried out using an automated DNA sequencer ABI Prism 3700 (Applied Biosystems, Foster City, California, USA). Genotyping was deemed successful if the concordance rate between duplicates was $\geq 95 \%$. For samples not showing a clear genotype, the PCR and sequencing was repeated until the results were unequivocal.

\section{Statistical analyses}

The Hardy-Weinberg equilibrium (HWE) was initially determined. Statistical analysis was then performed using SPSS 16.0 (SPSS Inc, Chicago, IL, USA) for Windows. Pearson chisquare test was used to compare genotypes frequencies and alleles of rs763361 between NMO, MS, and CTLs. The relative risk (estimated as the odds ratios, ORs) and 95\% confidence intervals (95\% CIs) were calculated. The $p$ values (uncorrected $\left.p, p^{\text {uncorr }}\right)$ were corrected by Bonferroni-Dunn's correction to calculate corrected $p$ values $\left(p^{\text {corr }}\right)$. Statistical significance was set at $P<0.05$.

\section{RESULTS}

As shown in the Table, the frequency of the TT genotype was higher in NMO patients than in CTLs (pcorr=0.021; OR: 2.668, 95\% CI: 1.293-5.587). The frequency of $\mathrm{T}$ allele was significantly higher in NMO patients than in CTLs (pcorr=0.030; OR: 1.591, 95\% CI: 1.071-2.363). There was no difference in the frequency of the $\mathrm{T}$ allele and TT genotype between NMO and MS. The frequency of T allele and TT genotype were also not increased in MS patients compare to the controls.

Table: Genotype and allele distribution of the rs763361 SNP in patients and controls

\begin{tabular}{cccc}
\hline rs763361 & NMO(\%) & MS $(\%)$ & CTLs $(\%)$ \\
\hline Genotypes & & & \\
CC & $31(34.8 \%)$ & $36(38.7 \%)$ & $52(42.6 \%)$ \\
CT & $35(39.3 \%)$ & $36(38.7 \%)$ & $56(45.9 \%)$ \\
TT & $23(25.8 \%)^{\mathrm{b}}$ & $21(22.6 \%)^{\mathrm{a}}$ & $14(11.5 \%)^{\mathrm{ab}}$ \\
Alleles & & & $160(65.6 \%)^{\mathrm{c}}$ \\
C & $97(54.5 \%)^{\mathrm{c}}$ & $108(58.1 \%)$ & $84(34.4 \%)^{\mathrm{c}}$ \\
T & $81(45.5 \%)^{\mathrm{c}}$ & $78(41.9 \%)$ & \\
\hline
\end{tabular}

${ }^{\text {a }} P^{\text {uncorr }}<0.05$ and $P^{\text {corr }}>0.05$; ${ }^{\text {b }} P^{\text {uncorr }}<0.01$ and $P^{\text {corr }}<0.05$; ${ }^{\text {c }} P^{\text {uncorr }}<0.05$ and $P^{\text {corr }}<0.05$

NMO: Neuromyelitis optica; MS: Multiple sclerosis; CTLs: Controls 


\section{Discussion}

In this case-control study of rs763361 allele distribution in Southern Han Chinese NMO and MS patients, we found that rs763361T was increased in NMO patients. Despite of the fact that the HLA gene is generally recognized as the strongest risk factor for NMO in Asian population, non-HLA SNPs in NMO have been less studied. The leukocyte adhesion molecule DNAM-1 (CD226) is expressed on the majority of $\mathrm{T}$ lymphocytes, NK cells, and monocytes ${ }^{19}$, involving both adaptive and innate immune responses. Lymphocyte functionassociated antigen-1 (LFA-1) is a co-stimulatory molecule playing an important role in T cell signaling, and CD226 assists in co-localization with this molecule ${ }^{20}$. Rs 763361 in exon 7 of the CD226 gene was shown to increase the susceptibility to multiple autoimmune diseases, such as rheumatoid arthritis ${ }^{21}$, systemic sclerosis ${ }^{22}$, and $\mathrm{SLE}^{15}$. In this study, we proved that the $\mathrm{T}$ allele and TT genotypes in rs763361 may increase the risk of NMO in Southern Han Chinese. However, the underlying mechanism is still unclear. Hafler et al hypothesized the rs763361 variant could alter the expression or signaling of CD226 as it occurs in the molecular cytoplasmic tail and Gly307Ser was the causal variant which shared the risk locus for autoimmune disease ${ }^{13}$. They also hypothesized rs763361 may alter mRNA splicing, and result in either CD226 isoform acting as a non-functional (non-signaling) protein, or with a novel function, while Gly307Ser could alter the signaling cascade by affecting the two known phosphorylation sites at positions 322 and 329, which play a critical role in CD226 immune response ${ }^{13}$.

\section{REFERENCES}

1. Alcina A, Vandenbroeck $K$, Otaegui $D$, et al. The autoimmune disease-associated KIF5A, CD226 and SH2B3 gene variants confer susceptibility for multiple sclerosis. Genes Immun. 2010; 11(5):439-45.

2. Ross RT, Cheang M, Landry G, et al. Herpes zoster and multiple sclerosis. Can J Neurol Sci. 1999;26:29-32.

3. Wang H, Dai Y, Qiu W, et al. HLA-DPB1 0501 is associated with susceptibility to anti-aquaporin-4 antibodies positive neuromyelitis optica in southern Han Chinese. J Neuroimmunol. 2011;233(1-2):181-4.

4. Lennon VA, Wingerchuk DM, Kryzer TJ, et al. A serum autoantibody marker of neuromyelitis optica: distinction from multiple sclerosis. Lancet. 2004;364:2106-12.

5. Zipp F, Windemuth C, Pankow H, et al. Multiple sclerosis associated amino acids of polymorphic regions relevant for the HLA antigen binding are confined to HLA-DR2. Hum Immunol. 2000;61(10):1021-30.

6. Rodrigo L, Hernández-Lahoz C, Fuentes D, et al. Prevalence of celiac disease in multiple sclerosis. BMC Neurol. 2011;7(11):31.

7. Svejgaard A. The immunogenetics of multiple sclerosis. Immunogenetics. 2008;60(6):275-86.
8. Yamasaki K, Horiuchi I, Minohara M, et al. HLA-DPB1*0501 associated optico-spinal multiple sclerosis: clinical, neuroimaging and immunogenetic studies. Brain.1999;122: 1689-96.

9. Matsushita T, Matsuoka T, Isobe N, et al. Association of the HLADPB $1 * 0501$ allele with antiaquaporin-4 antibody positivity in Japanese patients with idiopathic central nervous system demyelinating disorders. Tissue Antigens. 2009;73:171-6.

10. Lundström W, Greiner E, Lundmark F, et al. No influence on disease progression of non-HLA susceptibility genes in MS. J Neuroimmunol. 2011;237(1-2):98-100.

11. Fang L, Isobe N, Yoshimura S, et al. For the South Japan Multiple Sclerosis Genetics Consortium. Interleukin-7 receptor alpha gene polymorphism influences multiple sclerosis risk in Asians. Neurology. 2011;76(24):2125-7.

12. Elishmereni M, Bachelet I, Levi-Schaffer F. DNAM-1: an amplifier of immune responses as a therapeutic target in various disorders. Curr Opin Investig Drugs. 2008;9(5):491-6.

13. Hafler JP, Maier LM, Cooper JD, International Multiple Sclerosis Genetics Consortium (IMSGC), et al. CD226 Gly307Ser association with multiple autoimmune diseases. Genes Immun. 2009;10(1):5-10.

14. International Multiple Sclerosis Genetics Consortium (IMSGC). The expanding genetic overlap between multiple sclerosis and type I diabetes. Genes Immun. 2009;10(1):11-14.

15. Du Y, Tian L, Shen LX, Wang F, et al. Association of the CD226 single nucleotide polymorphism with systemic lupus erythematosus in the Chinese Han population. Tissue Antigens. 2011;77(1):65-77.

16. Wieczorek S, Hoffjan S, Chan A, et al. Novel association of the CD226 (DNAM-1) Gly307Ser polymorphism in Wegener's granulomatosis and confirmation for multiple sclerosis in German patients. Genes Immun. 2009;10(6):591-5.

17. Wingerchuk DM. Neuromyelitis optica. Int MS J. 2006;13:42-50.

18. Polman CH, Reingold SC, Banwell B, et al. Diagnostic criteria for multiple sclerosis: 2010 revisions to the McDonald criteria. Ann Neurol. 2011;69:292-302.

19. Shibuya A, LL Lanier, JH Phillips. Protein kinase C is involved in the regulation of both signaling and adhesion mediated by DNAX accessory molecule-1 receptor. J Immunol. 1998;161: 1671-6.

20. Shibuya K, Shirakawa J, Kameyama T, et al. CD226 (DNAM-1) is involved in lymphocyte function-associated antigen 1 costimulatory signal for naive $\mathrm{T}$ cell differentiation and proliferation. J Exp Med. 2003 Dec 15;198(12):1829-39.

21. Deshmukh HA, Maiti AK, Kim-Howard XR, et al. Evaluation of 19 autoimmune disease-associated loci with rheumatoid arthritis in a Colombian population: evidence for replication and gene-gene interaction. J Rheumatol. 2011 Sep;38(9):1866-70.

22. Dieudé P, Guedj M, Truchetet ME, et al. Association of the CD226 Ser(307) variant with systemic sclerosis: evidence of a contribution of costimulation pathways in systemic sclerosis pathogenesis. Arthritis Rheum. 2011 Apr;63(4):1097-105. 